\title{
Las críticas de Nietzsche a las corrientes historiográficas románticas. Una evaluación desde lo corpóreo-vital
}

\author{
Nietzsche's Criticisms of Romantic Historiographic Trends: An \\ Assessment from the Corporeal-Vital
}

\author{
Manuel Romero \\ Universidad de Chile \\ manuel.romero@ug.uchile.cl
}

\section{Resumen}

A finales del siglo XVIII y comienzos del XIX se desarrolló en Alemania un movimiento cultural conocido como Romanticismo, que influyó de manera determinante en el quehacer historiográfico dieciochesco y decimonónico, siendo Friedrich Nietzsche una de sus principales voces críticas. Pero las críticas nietzscheanas al romanticismo historiográfico van a ser ambivalentes: por un lado, rescatarán positivamente la valorización que hace la corriente de la cultura aristocrática-heroica germánica; pero, por otro lado, evaluarán negativamente el espíritu rousseauniano-cristiano que también trae consigo. Aquí se considerará que las valoraciones de Nietzsche de las tendencias románticas no proceden tanto de apreciaciones políticas o académicas como de criterios corpóreo-vitales.

\section{Palabras clave}

Romanticismo, historiografía, estudios griegos, filosofía del cuerpo, Rousseau.

\begin{abstract}
At the end of the $18^{\text {th }}$ and in the early $19^{\text {th }}$ centuries, it was developed in the German cultural world the movement called Romanticism, which influenced in a crucial way in the contemporary historiographic work, one of its foremost critical voices being that of Friedrich Nietzsche. But Nietzschean criticisms of historiographic romanticism had an ambivalent nature: on the one hand, it will positively rescue the valuation made by the current of the Germanic aristocratic-heroic culture; but, on the other, it will negatively evaluate the Rousseaunian spirit with its Christian germ that also took with it. Here it is also to consider that Nietzsche's evaluations on romantic trends did not stem as much as from political or academic appreciations, but as from vital-corporeal criteria.
\end{abstract}

\section{Keywords}

Romanticism, historiography, Greek studies, philosophy of the body, Rousseau. 


\section{Introducción}

En una época donde los estados germanos estaban fragmentados y temerosos por la amenaza de la Revolución francesa, y, posteriormente, por su vástago Napoleón, la historia se convertiría en un instrumento que ayudaría a las autoridades alemanas a ir construyendo una identidad nacional unificada. La base filosófica de esta perspectiva historiográfica pronacionalista se cimentaría sobre el ideario del movimiento romántico. A rasgos generales, se puede caracterizar al romanticismo como un movimiento que valoraba: las expresiones sentimentales por sobre las racionales; las manifestaciones individual-subjetivas por sobre las objetivo-científicas y las reivindicaciones nacionales por sobre las universales.

Una de las voces que manifestaría mayor desacuerdo y aprensiones ante el movimiento romántico será la de Friedrich Nietzsche. Para el filólogo, el romanticismo, desde una perspectiva historiográfica, será una corriente que promoverá el debilitamiento corpóreo; esto, porque transforma el conocimiento del pasado no en una expresión cultural que ayuda a potenciar la vida; sino que convierte este conocimiento en un instrumento político usado de forma artificiosa para consolidar determinadas estructuras de poder. Sin embargo, cabe hacer notar que las críticas nietzscheanas hacia la tendencia histórico-romántica no serán estrictamente negativas. El filólogo manifestará también ciertas simpatías a algunas expresiones del romanticismo historiográfico como, por ejemplo, aquellas que hacen rescate del pasado heroico germano.

En este contexto de aparente ambigüedad que manifiesta Nietzsche hacia los estudios históricos románticos, y con el objetivo de aclarar los posicionamientos reflexivos que tiene el filósofo con respecto a esta corriente, nos preguntamos en este artículo: ¿Cuál es la posición concreta que tiene Nietzsche frente al movimiento romántico y su quehacer cultural?, y, específicamente, ¿qué piensa de los trabajos historiográficos nacidos desde esta corriente?

A manera de hipótesis señalamos que la posición que tiene Nietzsche con respecto al romanticismo historiográfico será ambivalente y no unívoca: por un lado, el filólogo rescata positivamente la valoración que hace la corriente de la cultura aristocrática-heroica germánica; pero, por otro lado, criticará el espíritu rousseauniano-cristiano que también trae consigo. La ambivalencia que demuestra Nietzsche en este aspecto no se daría de una forma contradictoria, sino coherente, esto, porque el mismo filólogo reconoce que las expresiones que alberga el movimiento romántico contienen componentes divergentes.

Para ahondar en lo reseñado, el presente artículo se dividirá en cuatro apartados: en el primero, se da cuenta de los rasgos generales de la influencia del romanticismo en la historiografía alemana; en el segundo apartado, se realiza una revisión específica de las críticas nietzscheanas a las tendencias historiográficas románticas; en una tercera sección, se señala desde qué dimensión Nietzsche valora las tendencias historiográficas románticas; finalmente, en un cuarto apartado, se da cuenta de las reflexiones finales del trabajo. 


\section{El romanticismo alemán y su influencia en el quehacer historiográfico. Apreciaciones generales}

A finales del siglo XVIII y comienzos del XIX se desarrollará en Alemania un movimiento cultural conocido como romanticismo. Éste se da como una reacción revolucionaria contra el racionalismo de la ilustración y el neoclasicismo artístico. En rasgos generales, para los promotores del romanticismo, la prioridad del quehacer cultural debía estar centrada y motivada por los sentimientos, aprecio de lo personal y lo subjetivo, culto al carácter nacional o volkgeist, y no en el racionalismo, creencia en la universalidad ilustrada y la primacía de la razón.

A principios del siglo XIX la influencia del romanticismo se haría profunda en el medio cultural alemán. Este proceso sería visto con buenos ojos por los líderes germanos de aquel periodo. Consideraban que desde aquella ola cultural se podría unificar Alemania, algo muy pretendido para la época debido a la debilidad alemana con respecto a otras naciones; y, en este contexto, promocionarían funcionalmente las expresiones romántico-nacionalistas. Se considerará que una de las herramientas más eficientes en incentivar la unificación alemana será la historia. Debido a esta consideración habrá un esfuerzo decidido "desde arriba" en convertir a este saber en la disciplina principal de la bildung o formación alemana. Es así que por medio de la historia se iría alimentando instrumentalmente un "imaginario de lo nacional". Los recursos temáticos que fundamentarán este imaginario serán variados: se hará énfasis en las tradiciones comunes; se argüirá la existencia de formas económicas similares entre los cantones germanos; se enfatizará la cercanía racial señalando que hay una ascendencia común entre los alemanes, etc. En resumen, la labor del historiador romántico se plasmará principalmente al servicio del poder, y en esta perspectiva, su misión se circunscribirá en dar fundamento en el pasado a la idea de lo nacional. ${ }^{1}$

Las ideas nacionalistas de principios del siglo XIX en Alemania contarán con una amplia proyección en los círculos académicos germanos. ${ }^{2}$ Esto, fundamentalmente, por el valor político que se ve en el uso de estas ideas. Por un lado, sirven como instrumentos que

\footnotetext{
${ }^{1}$ Autores de gran importancia dentro de la perspectiva histórica-nacionalista en Alemania serán: Friedrich Schiller (1759-1805), Johann Herder (1744-1803), Johann Gustav Droysen (1808-1884), Heinrich von Treitschke (1834-1896), Ludwig Hauser (1818-1867), Heinrich von Sybel (1817 -1895), Theodor Mommsen (1817-1903), entre otros.

${ }^{2}$ La historia nacional fue durante el siglo XIX enseñada con énfasis en los colegios alemanes; el Estado la promocionaba para inculcar patriotismo a los estudiantes. Los gobiernos en este sentido no eran agentes neutros y pasivos. Promovían el estudio de la historia de forma dirigida (visiones que no se ajustasen al plan de lo nacional no eran consideradas dentro de la bildung oficial). Para promover la agenda pangermanista, el Estado alemán creará diversos centros especializados en donde se llevarán a cabo variadas investigaciones históricas de relevancia nacional (una de las publicaciones destacadas de estos centros será los "Monumenta Germaniae histórica" [1833], serie recopilativa de fuentes cuidadosamente editadas para el estudio de la historia de Alemania). Los gobiernos se preocuparían también por el resguardo de edificios históricos, de la cultura y arte propios, además de hacerse cargo de excavaciones de interés nacional. Nietzsche en su adolescencia estará muy influido de este espíritu romántico y los principios de esa Bildung; de hecho, el filólogo, en esta etapa de su vida, creará una asociación con amigos de infancia (Wilhelm Pinder y Gustav Krug) llamada Germania, en donde preparó disertaciones, poesías y comentarios, precisamente para fomentar ese espíritu pangermánico [Curt Janz, Friedrich Nietzsche: Infancia y juventud, vol.1 (Madrid: Alianza, 1978)].
} 
dan cohesión a los diferentes estados germanos, y, por otro lado, sirven para dar legitimidad a la burguesía ${ }^{3}$ como clase dominante.

\section{Nietzsche. Críticas a las tendencias históricas románticas}

La posición que Nietzsche tiene con respecto al romanticismo no es homogénea, sino más bien ambivalente. Por un lado, valorará que la corriente rescate las historias heroicas de algunas personalidades alemanas del pasado; pero, por otro lado, criticará también que la corriente articule relatos históricos bajo un espíritu rousseauniano-cristiano. La ambivalencia que demuestra Nietzsche en este contexto no se da de forma contradictoria, sino coherente; esto, porque el mismo filólogo reconoce que las expresiones que alberga el movimiento romántico contienen componentes que son discordantes. Así lo señala: "Mi lucha contra el romanticismo, en el que confluyen los ideales cristianos y los ideales de Rousseau, pero al mismo tiempo con una nostalgia de los viejos tiempos de la cultura sacerdotal aristocrática, de la virtü, del «hombre fuerte» — algo extremadamente híbrido". 4

Nietzsche reconoce la "hibridez" del movimiento romántico, que por un lado, realza los valores y la "virtü" aristocrático-guerrera, y, por otro lado, enaltece las perspectivas cristiano-democráticas que reivindican al mundo plebeyo y la naturaleza, esta última entendida de forma idealizada. Estos dos lineamientos del romanticismo tendrían su símil en dos tendencias historiográficas en Alemania: aquella que rescata el pasado heroico germánico, la historia de los grandes hombres y sus hazañas; y aquella que recoge las experiencias comunes del volkgeist de las comunidades germánicas.

\section{Perspectiva aristocrática}

Con respecto a la tendencia aristocrático-heroica decir, que historiadores, filósofos y románticos en general trabajarán en sus obras con el objetivo de destacar:

Las hazañas bélicas de líderes célebres de la antigüedad, con énfasis en aquellos de ascendencia germana, como por ejemplo: Carlomagno, Federico I "Barbarroja”, Federico II "El Grande", Carlos V, Segismundo, etc. Pero también algunos celebrarán las hazañas de figuras no alemanas (Johannes von Müller y Hegel, por ejemplo, enaltecerán constantemente a Napoleón). Estos hombres-guerreros personificarían el arquetipo del genio, aquella figura heroica que encaraba con valentía y virtud las realidades dolorosas de su época.

La memoria heroica, que además de ser exaltada por medio de la historia, es rememorada mediante la construcción de monumentos que reivindican las grandes hazañas

\footnotetext{
${ }^{3}$ Para las burguesías europeas la historia también era instrumento de legitimación soberana (antes la soberanía se daba por derecho divino al rey, por lo que se pretendía cambiar aquel principio señalando que la soberanía era dada por la nación a ciertos hombres con cualidades especiales de liderazgo). En este contexto, los historiadores románticos se esforzarían por presentar genealogías nacionales, esto con la intención de demostrar que las naciones pre-existen en los pueblos desde tiempos pretéritos. De esta forma, el nuevo estado burgués, en base a una artificiosa narración histórico-nacionalista, quedaba legitimado por ser la expresión institucionalizada del nuevo sujeto histórico por antonomasia: el "pueblo-nación", entendido como la comunidad de los hombres que comparten una historia y una cultura.

${ }^{4}$ Friedrich Nietzsche, Fragmentos póstumos, 1885-1889, Vol. IV (Madrid: Tecnos, 2008), 297.
} 
de personajes alemanes. Uno de estos monumentos es el "Walhalla", obra idéntica al Partenón griego, el cual será erigido cerca de Ratisbona por Luis I de Baviera (1830-1842), y que servirá como una especie de salón de la fama de las personalidades germánicas distinguidas.

La mitología nórdico-germánica, la cual recuerda el carácter heroico y guerrero de los pueblos germánicos (Weyland, Siegfried, Hagbard, entre otros, serán arquetipos del hombre germano).

\section{Perspectiva comunitaria}

Con respecto al segundo lineamiento nombrado, que rescata "lo común" del mundo germano, los románticos se esforzarán en destacar:

Las expresiones artísticas que evidencien la estética particular germana, como por ejemplo, la gótica medieval: la arquitectura gótica era el símbolo de ese "pasado sagrado", una arquitectura "orgánica" que corporizaba las formas naturales.

Las manifestaciones del folklore tribal comunes: compilarán y difundirán los mitos, costumbres, leyendas, supersticiones, música, cuentos orales, romances o baladas anónimas, coplas y refranes, etc., de los distintos Estados alemanes.

La proximidad lingüística: investigarán las estructuras y raíces comunes de la lengua germánica y sus variantes; en este contexto promoverán los estudios lingüístico-filológicos.

El pasado cultural común: los alemanes se sentirán emparentados con la cultura clásica esto desde un aspecto artístico, filosófico, lingüístico y literario; y como legatarios europeos, se asumirán como los protectores y continuadores de esta cultura.

La religión común: se esforzarán en recordar que los diferentes Estados alemanes han tenido durante gran parte de su historia un pasado religioso similar: el cristiano. ${ }^{5}$

En su libro Aurora, Nietzsche sintetizará las expresiones de este lineamiento que rescata lo común: "los historiadores y los románticos alemanes: sus esfuerzos se han dirigido, por lo general, a reinstaurar sentimientos antiguos y primitivos, como el cristianismo, el alma, las leyendas y las formas del habla populares, la Edad Media, el ascetismo oriental, ${ }^{6}$ el hinduismo". 7

En general, estas dos tendencias representarán, en el fondo, diferentes tipos de "fugas sentimentales" hacia el pasado. Sin embargo, a pesar de las diferencias aparentes en el enfoque de estudio en que se centran estas tendencias, las dos convergerán en un objetivo

\footnotetext{
${ }^{5}$ Ya sea por ser parte de un imperio cristiano común: el sacro imperio romano-germánico; o por tener una influencia cristiana-luterana fuerte.

${ }^{6}$ Cuando Nietzsche refiere a los "románticos alemanes" que se han esforzado en rescatar el "ascetismo oriental"

y el "hinduismo", está apuntando principalmente a las figuras de Friedrich Majer y Arthur Schopenhauer (el "buda de Frankfurt").

${ }^{7}$ Friedrich Nietzsche, “Aurora”, en Obras completas, vol. III, ed. Diego Sánchez Meca (Madrid: Tecnos, 2014), 592.
} 
común: interpretar el pasado fundamentalmente desde el filtro político pronacionalista. En este contexto, tanto la idea de la existencia de un talante aristocrático-guerrero en Alemania, como que el volkgeist alemán había llegado a una etapa de madurez unificadora, servirán para reforzar el imaginario de lo nacional.

De estos dos lineamientos enunciados, Nietzsche criticará principalmente los de la tendencia romántico-comunitaria. De ésta principalmente cuatro ideas: (1) que las naciones pre-existen y tienen que vivir un proceso orgánico hasta madurar como propiamente tales; (2) que la nación es un fin; (3) el carácter erudito y no activo del estudio del pasado clásico y del folklore tribal; y, (4) el espíritu rousseauniano, cristiano, revolucionario y democrático, que lleva impreso esta tendencia. A continuación observaremos estas críticas en detalle.

\section{Crítica a la visión orgánica de la historia}

Una de las críticas de Nietzsche en contra del romanticismo y su influjo sobre la historia se dirigirá hacia la perspectiva organicista que en ocasiones manifiesta. El propulsor principal de la interpretación organicista de la historia será Johann Herder (1744-1803). Éste en general señala que los pueblos se desarrollan en la historia de una manera equivalente al proceso orgánico-vital, es decir, que tienen sus momentos de nacimiento, crecimiento y deterioro. Esta mirada de Herder del desenvolvimiento histórico irá en contra, por un lado, de la visión ilustrada que señala que la historia avanza en un proceso lineal ascendente y continuo; y, por otro lado, de la idea de que la historia tiene que tener algún sentido universal, y que ese sentido lo encarnan ciertas culturas en detrimento de otras. Para Herder cada cultura es específica, conformada por su conjunto particular de circunstancias y procesos que deben madurar para así manifestarse en forma plena. El autor alemán considera, que en los diferentes Estados germanos es posible vislumbrar un espíritu preexistente común (volkgeist), manifiesto en sus cualidades estéticas, lingüísticas, religiosas, tribales y folklóricas, que son expresión de su cultura única. Nietzsche rechaza esta idea organicista de que el devenir de las sociedades se le asimile a los ciclos vitales del proceso orgánico, el cual comúnmente es clasificado en niñez, juventud y madurez; por el contrario, señala, que las diversas sociedades devienen en forma no estructurada:

[...] contra el paralelismo entre historia y la juventud, la madurez y la vejez: jtampoco se encuentra en ella la huella de la verdad! Cinco mil o seis mil años no significan nada, y ante todo no hay unidad, porque siempre vuelven a aparecer nuevos pueblos, sino de hombres, la nacionalidad es la mayoría de las veces sólo la consecuencia de rígidas normativas de gobierno, es decir, de un tipo de disciplina impuesta por la violencia generalizada y la represión. ${ }^{8}$

${ }^{8}$ Friedrich Nietzsche, Fragmentos póstumos, 1869-1874, Vol. I (Madrid: Tecnos, 2010), 502. 


\section{Crítica a la idea de nación como fin}

Vinculada con la anterior crítica, Nietzsche también resistirá a la idea de nación como el fin de un pueblo. Para el filólogo de Röcken, la idea de nación como telos se construye mediante un trabajo de adecuación forzada de la historia. El objetivo es darles a esos acontecimientos y hechos un sentido que es personificado en la nación. Los individuos, en este contexto, pueden no ser conscientes de que son parte de un movimiento que los encuadra como pueblo, pero, en algún momento de la historia, la razón de ese pueblo "madura", en ese instante se hacen conscientes de que son parte de un espíritu común que debe seguir desarrollándose hacia la forma plena del mismo: la nación. Es así que la historia para los románticos se transforma en un instrumento para "hacer conscientes" a los individuos de la prevalencia de ese "espíritu común”. Así para 1870-1871 criticará un juvenil Nietzsche esta idea:

Entretanto, volvamos a los griegos, para decirnos lo ridículo que es, frente a la Pitia, el concepto moderno de las nacionalidades y qué inoportuno resulta el deseo de querer ver a una nación como una unidad visible mecánica, pertrechada con un glorioso aparato de gobierno y con la pompa militar. ${ }^{9}$

Y aproximadamente quince años después, reafirmará esta crítica a las acciones idealistas que se dispusieron para componer el abstracto "nación":

¡Como hemos cambiado nuestro modo de pensar en cincuenta años! ¡Todo el romanticismo con su creencia en el «pueblo» ha sido refutado! ¡Nada de la poesía homérica como poesía del pueblo! ¡Nada de endiosar las grandes fuerzas de la naturaleza! ¡Nada de inferir del parentesco de lenguaje el parentesco de raza! ¡Nada de «intuición intelectual» de lo suprasensible! ¡Nada de verdad oculta en la religión! ${ }^{10}$

De hecho, Nietzsche considera que la existencia de la nación, con sus fronteras y delimitaciones culturales, muchas veces puede volverse en obstáculo y atadura para el desarrollo individual:

[...] mejor emigrar, intentar ser señor en parajes que sean vírgenes y estén limpios, sobre todo, dueño de uno mismo; cambiar de lugar en cuanto se vea algún indicio de esclavitud; no evitar la aventura ni la guerra y estar dispuesto para, en el peor de los casos, morir: cualquier cosa antes que esta servidumbre tan indecente... ${ }^{11}$

Nietzsche valora en este contexto, el "nomadismo apátrida"12, el cual no se fija en una sola región, ni se petrifica en una sola idea:

[...] distamos mucho de ser suficientemente «alemanes», tal como se entiende hoy corrientemente la palabra «alemán», para hablar en favor del nacionalismo y del odio racial, para poder alegrarse de la sarna del corazón y del envenenamiento de la sangre nacionales gracias a la cual cada pueblo se separa de otro, se segrega como si estuviera en cuarentena

\footnotetext{
${ }^{9}$ Ibíd., 180.

${ }^{10}$ Friedrich Nietzsche, Fragmentos póstumos, 1885-1889, Vol. IV (Madrid: Tecnos, 2008), 46.

${ }^{11}$ Friedrich Nietzsche, "Aurora”, en Obras completas, vol. III, ed. Diego Sánchez Meca (Madrid: Tecnos, 2014), 600.

${ }^{12}$ Gary Shapiro, "Estados y nómades: el mundo de Hegel y la tierra de Nietzsche", en Nietzsche y el devenir de la vida, ed. Vanesa Leem (Santiago: FCE, 2014), 291-307.
} 
[...] Nosotros, apátridas, somos por raza y proveniencia demasiado múltiples y mezclados, como «hombres modernos», y por consiguiente poco tentados a participar en esa mentirosa e impúdica autoadmiración racial que se expone hoy en Alemania como signo de sentimiento alemán y que suena doblemente falsa e indecente en el pueblo del «sentido histórico»". ${ }^{13}$

Nietzsche señala también que el proceso de unificación de los Estados alemanes en una sola gran nación no se dio en Alemania por una causalidad orgánica, maduración del volkgeist, sino que se hizo por el temor que suscitaron las guerras napoleónicas, guerras que llevaron a los distintos Estados germanos a forjar alianzas para hacer frente a Napoleón, ${ }^{14}$ y que continuarían posterior a la caída del corso. ${ }^{15}$ Así lo señala el filólogo: "[...] porque el movimiento nacional del que surge esta gloria guerrera es solo el contragolpe frente a Napoleón y no existiría sin Napoleón". ${ }^{16}$

\section{Crítica al carácter idealizante y pasivo de los estudios clásicos}

Otra de las críticas que hace Nietzsche a los estudios históricos de tendencia romántica es su idealización instrumental del pasado clásico. Pero, para comprender las observaciones que hace el filólogo a este respecto, se hace necesario contextualizar cómo es que se desarrollaron los estudios clásicos en Alemania.

\section{Los momentos de los estudios clásicos en Alemania}

De manera general, se puede decir que el primer "renacimiento" de los estudios del mundo clásico en occidente lo daría la Italia del siglo XV. En el caso italiano, el rescate del pasado clásico se desarrolla en clave romanizada, es decir, enfocándose principalmente en Roma y su legado, y, por eso, también, la frecuente traducción al latín en pleno Renacimiento de los clásicos griegos. Un segundo movimiento "renacentista" se daría en los siglos XVIII y XIX, y sería protagonizado por Alemania, que a diferencia del caso italiano que estudia Grecia en la perspectiva de su influencia hacia Roma, ellos lo hacen conectando directamente con el mundo griego.

El enfoque y carácter de los estudios clásicos en Alemania no serán siempre iguales y diferirán en el tiempo. En un primer momento, del siglo XVIII hasta principios del siglo XIX, los estudios se enfocan en la experiencia estética griega, tanto del orden artístico como literario, y en su filosofía. Posteriormente, desde principios del siglo XIX en adelante, los estudios se centrarán en los aspectos más filológicos, estudio específico de la lengua y hermenéutica crítica de los textos.

\footnotetext{
${ }^{13}$ Friedrich Nietzsche, "La gaya ciencia”, en Obras completas, vol. III, ed. Diego Sánchez Meca (Madrid: Tecnos, 2014), 890.

${ }^{14}$ Aquello recordando que en 1806 cae el Sacro Imperio Romano Germánico por causa de Napoleón (batalla de Jena), dejando a una pluralidad de pequeños Estados y etnias con diversas lenguas fragmentados.

${ }^{15}$ Un ejemplo de estas alianzas es el caso de la Confederación Germánica creada en 1815.

${ }^{16}$ Ibíd., 879.
} 


\section{Primer momento: rescate idealizador}

El primer momento de los estudios griegos en Alemania está marcado por el carácter idealializante y estetizante que se hace de éstos. Aquella primigenia perspectiva en los estudios no es extraña, ya que la evocación de Grecia, o a la idea que se quiere proyectar de la misma, es para las autoridades pro-unificación, una herramienta cultural que en los cálculos políticos se consideraba efectiva en la función de estructurar una identidad.

El rescate del legado clásico se dará de forma decidida y entusiasta en los Estados germanos dieciochescos y decimonónicos. La mayoría de los autores que emprenderán este rescate estarán dominados por una especie de conciencia de misión histórica que les impulsa a sentirse como los auténticos herederos de la Grecia clásica; esto, a diferencia de lo que ocurriría en otros países europeos que no sentían esta filiación ${ }^{17}$. Así lo dejará patente Friedrich Schiller (2016 [1795]), en sus Cartas sobre la educación estética del hombre:

[...] si prestamos un poco de atención al carácter de nuestro tiempo, nos sorprenderá el contraste existente entre la forma actual de la humanidad y la forma que tuvo en épocas pasadas, especialmente en la de los griegos [...] Los griegos no nos avergüenzan tan sólo por una sencillez que es ajena a nuestro tiempo; son a la vez mismo nuestros rivales, incluso nuestro modelo. ${ }^{18}$

Y también, W. von Humboldt: "Los griegos no se limitan a ser para nosotros un pueblo cuyo conocimiento histórico nos sea útil sino que son ideal". ${ }^{19}$

En este contexto, en gran parte del mundo académico alemán se aspira a una especie de palingenesia del legado griego a través del mundo germánico. Ese resurgimiento de la Antigüedad griega a través de Alemania se expresará culturalmente en diferentes dimensiones. En la dimensión del arte, los trabajos de Winckelmann, Reflexiones sobre la imitación de las obras griegas en la pintura y en la escultura (1755-1756), Historia del arte en la antigüedad (1764) y de Lessing, Laocoonte (1766), serán paradigmáticos al respecto. En la dimensión literaria, los autores que más destacarán en la apropiación de los textos clásicos serán: Herder, Goethe, Schiller, creador de obras poéticas como Los dioses de Grecia (1788) en las que se evoca al mundo griego como contrapunto de la humanidad de su tiempo, y Hölderlin, creador de escritos con este espíritu clásico como Hiperión (1797) y la La muerte de Empédocles (1846), entre otros. También la filosofía se sumará a esta peculiar complementación germánica con el mundo griego. Un protagonismo especial tendrá en este respecto Hegel. Para el filósofo berlinés la conciencia de la libertad despertaría por primera vez con los griegos para llegar al absoluto de su autoconciencia con el Estado prusiano. ${ }^{20}$ Nietzsche criticará esta visión romántica de los griegos que hacen estos autores, argumentando que la misma no logra penetrar en la esencia del ethos genial y creativo heleno: ${ }^{21}$

\footnotetext{
${ }^{17}$ Arsenio Ginzo, "Nietzsche y los griegos", POLIS, 12 (2000): 85-135.

${ }^{18}$ Friedrich Schiller, Sobre la educación estética del hombre en una serie de cartas (Mendoza: Universidad Nacional de Cuyo, 2016 [1795]), 70 [Sexta cartas].

${ }^{19}$ A. Ginzo, "Nietzsche y los griegos", 88.

${ }^{20}$ G. W. F. Hegel, Lecciones sobre la Filosofía de la Historia Universal (Madrid: Alianza, 1999).

${ }^{21}$ A. Ginzo, "Nietzsche y los griegos", 89-90.
} 
Es una comedia alegre de la que sólo ahora aprendemos a reírnos, que sólo ahora vemos: a saber, que los contemporáneos de Herder, Winckelmann, Goethe y Hegel reclamaban haber redescubierto el ideal clásico... ¡Y al mismo tiempo a Shakespeare! $!^{22}$

En resumen, se puede decir que en este primer momento de los estudios griegos en Alemania se desarrolla una visión idealizada del mundo clásico. Desde el aspecto estético y literario, el influjo idealizante se hará notar en la valoración de las expresiones artísticas griegas a las cuales se les atribuye haber alcanzado: la armonía de las formas, la serenidad del ideal y el equilibrio exacto de la relación del hombre con la naturaleza y la geografía. Desde un aspecto filosófico, la fascinación se dará por las obras de los grandes filósofos clásicos (Platón y Aristóteles, principalmente). Es así que los griegos iniciadores de la cultura occidental, serán considerados como el "alma mater" de Alemania: "fueron", pero "siguen siendo" en ella.

\section{Segundo momento: énfasis en la erudición crítica}

Durante las primeras décadas del siglo XIX, el enfoque de los estudios griegos, de carácter más literario y estético, comienza a variar para centrarse en aspectos más filológicos y críticos que idealizantes. Tanto es así, que este nuevo espíritu hermenéutico de los estudios clásicos, fascinado por el auge de las ciencias de la naturaleza, no dudaba en: "rechazar como «sentimental» $\mathrm{y}$ «superficial» la visión que del mundo heleno había dejado la época de Goethe y de Schiller, insistiendo ahora, por el contrario, en la creciente recopilación de hechos y en la especialización, en definitiva, en una especie de cientificismo muy en la línea de la visión imperante en el siglo XIX. ${ }^{23}$

Sin embargo, este énfasis cientificista, leer a los griegos lo más literal y descriptivo posible evitando las interpretaciones estetizantes, si bien, por un lado, entregó importantes aportaciones, sobre todo por evitar la idealización de los griegos y leerlos críticamente; por otro lado, empobreció el estudio heleno, esto, porque se hacía una lectura en extremo academicista de éstos, sin comprender ni conectar con el espíritu que llevó a esos griegos a realizar tales obras. Nietzsche, cuando entra en escena como profesor de filología clásica (1869-1879), vislumbra estos síntomas de estancamiento y de erudición estéril en que se habían convertido los estudios clásicos. Así reflejaría este giro hacia la erudición:

Las personas vanidosas valoran más un fragmento del pasado desde el momento en que son capaces de volver a sentirlo (sobre todo cuando es difícil), y hasta pretenden en lo posible resucitarlo de entre los muertos. Y como los vanidosos siempre son legión, el peligro que corren los estudios históricos en cuanto una época entera cae en sus manos no es precisamente insignificante: se desperdicia demasiada energía en toda clase de resurrecciones posibles. Quizá sea este el punto de vista desde el que mejor se entiende el movimiento entero del romanticismo. ${ }^{24}$

Para Nietzsche, el estudiar a los griegos desde una consideración idealizada y con un fin instrumental en lo político termina por transformar su legado cultural en algo vacío. Una

\footnotetext{
${ }^{22}$ F. Nietzsche, Fragmentos póstumos, 1885-1889, Vol. IV, 452.

${ }^{23}$ A. Ginzo, "Nietzsche y los griegos", 91.

${ }^{24}$ F. Nietzsche, "Aurora", 574-575.
} 
simple reliquia preciosa que hay que emular "imitándola", sin comprender el espíritu artístico que ayudó a constituir las obras de dicha cultura:

Mas cuando se llega a juzgar tan mal a nuestros clásicos, honrándolos de manera tan ultrajante, es que ya no se los conoce: y ésta es la situación general [...] solo hay una manera de honrarlos, que consiste en seguir buscando con el espíritu y el mismo ánimo que ellos, sin cansarse nunca de aquello. ${ }^{25}$

Para Nietzsche, estos eruditos, los cuales también señala como "filisteos", alientan la décadence cultural, ya que observan y estudian el pasado de una manera "anticuaria" y pasiva $^{26}$; su objetivo es rememorar la obra griega asimilándola con el presente, pero vaciando a este pasado de todo el espíritu activo que se dispuso en él: ${ }^{27}$

Todo el romanticismo del ideal, en cuanto considera que es posible involucionar, es falso. De hecho, los románticos representan una forma enfermiza de décadence: ellos son muy avanzados, muy tardíos y completamente estériles... La aspiración hacia lo anterior es incluso un testimonio de un profundo displacer y de falta de futuro. ${ }^{28}$

\section{El romanticismo clásico en Nietzsche y su posterior autocrítica}

Nietzsche se va a mostrar como un continuador heterodoxo de los estudios griegos alemanes. Su interpretación de Grecia diferirá de la de sus contemporáneos. Esto, por un lado, por la exégesis que hace de la literatura y filosofía clásicas, y, por otro lado, por el trato filológico que le da a las fuentes. Tampoco sus apreciaciones acerca del mundo griego serán iguales en el tiempo. A grandes rasgos se puede decir que, en un primer momento, Nietzsche estará también muy influenciado por el espíritu romántico; mientras que en un segundo momento, desde Humano demasiado humano (1878) en adelante, dejará atrás el influjo romántico para abordar a los griegos desde una perspectiva más crítica. A continuación veremos con más detalles estos dos momentos.

\footnotetext{
${ }^{25}$ Friedrich Nietzsche, “Consideraciones intempestivas: David Strauss, el confesor y el escritor”, en Obras completas, vol. I, ed. Diego Sánchez Meca (Madrid: Tecnos, 2011), 647.

${ }^{26}$ Nietzsche refiere como "anticuaria" a la forma de relación que establece el hombre con la historia, la cual valora la selección y conservación de datos y hechos históricos como "memoria". Es preciso decir, que Nietzsche no está en contra del impulso anticuario propiamente tal, sino con lo que está en contra es del "exceso de memoria". Nietzsche señala que este exceso puede resultar perjudicial para la vida; esto, por un lado, porque no le permite al individuo discernir lo que puede resultar provechoso de conservar como memoria de lo que no (todo se mantiene como importante y no hay desapego de nada, en este sentido no hay "historia crítica"). Por otro lado, como la mirada del individuo esta puesta hacia el pasado de manera nostálgica (el pasado es objeto de culto y veneración), desatiende el presente. Según Nietzsche este "exceso de memoria" enferma al hombre, aquello, porque no lo exige al riesgo ni abrirse a la vida desconocida y experimental; no lo exige a devenir como "algo más". (Friedrich Nietzsche, "Consideraciones intempestivas: De la utilidad y los inconvenientes de la historia para la vida”, en Obras completas, vol. I, ed. Diego Sánchez Meca [Madrid: Tecnos, 2011], 641-686).

${ }^{27}$ Para Nietzsche fijarse en un pensamiento es un estancamiento, un retroceso, es convertirse en un "camello de la cultura" que mastica y balbucea siempre lo mismo sin generar nada nuevo y útil.

${ }^{28}$ Nietzsche, Fragmentos póstumos, 1885-1889, vol. IV, 659.
} 


\section{Primer momento: la idealización de la Grecia pre-socrática}

Nietzsche, durante su época juvenil, prolonga la nostalgia de Grecia que habían experimentado tantos espíritus alemanes desde la segunda mitad del siglo XVIII. Sin embargo, su idealización romántica del mundo heleno diferirá en su naturaleza y enfoque a la de sus contemporáneos. Ya el filólogo había llegado tempranamente a la conclusión de que la visión de Grecia transmitida por el clasicismo alemán era deficiente. Considerará que, a pesar del apasionamiento alemán por el legado de los griegos, los teutones no habían logrado descifrar realmente la auténtica naturaleza griega ni penetrar en su verdadero núcleo significante. ${ }^{29}$ A contrapelo de sus contemporáneos, considerará que el comienzo del ethos singular heleno no se encontraría en el periodo clásico (siglo V a.C.), sino en el arcaico (el tiempo de la Grecia trágica-agonal). Nietzsche piensa que "es preciso rescatar de su tumba al siglo VI"30 porque ahí es donde verdaderamente se constituiría y habría despertado el carácter creador y genial griego, y que para el periodo clásico y el helénico lo que se visualizaría no es el cenit de la cultura griega, sino los momentos del progresivo decaimiento de ese carácter genial $^{31}$.

Para Nietzsche, el genio arcaico intuitivamente había sido capaz de captar la naturaleza trágica de la existencia, resignándose por tanto ante ella. Según el filólogo, este pesimismo trágico es afirmador, ya que estima que las disposiciones del mundo no son dadas por algún principio metafísico rector que determine todo lo que es; sino que lo son producto de las dinámicas generadas desde el $\operatorname{caos}^{32}$ y el azar. ${ }^{33}$

La cultura y la civilización humanas no se han originado y desarrollado siguiendo un plan trascendente, sino que lo ha hecho como una construcción histórica, y esa construcción se ha cimentado sobre "simulacros" y "ficciones" de verdad articuladas desde el lenguaje. En este contexto, como lo que se dice acerca del mundo es dado como un constructo, el futuro nunca está clausurado, ya que lo construido no es inmutable ni eterno y se puede destruir; la destrucción a su vez puede dar paso a nuevas posibilidades para re-situarse en el mundo. ${ }^{34} \mathrm{El}$

\footnotetext{
${ }^{29}$ A. Ginzo, "Nietzsche y los griegos", 104.

${ }^{30}$ Ibíd., 104.

${ }^{31}$ Esta postura de ver en Grecia un proceso de desarrollo decreciente en su historia, irá a contrapelo de la perspectiva ilustrada que considera que toda la historia se desenvuelve en un proceso ascendente y progresivo.

${ }^{32}$ Cuando Nietzsche hace uso del concepto "caos" no es para designar alguna esencia oculta de la realidad; "Se trata, por el contrario, de una formulación cuyo sentido es precisamente el de evitar llamar al mundo como un todo, con un nombre único que recoja su esencia" (Luis Eduardo Gama, "El carácter total del mundo. Esbozo de una ontología del caos en Nietzsche", Ideas y Valores, [vol.] 66, 2017, 165, 350).

33 Tal como ocurre con el concepto de caos, Nietzsche usa el concepto "azar" para contravenir la perspectiva epistémica que explica el mundo en términos de causalidad y telos; es para remarcar que la existencia es dada desde una dinámica casual y no causal (con sentidos). Dice, por ejemplo: Si vosotros sabéis que no hay fines, entonces sabéis también que no hay azar: puesto que solo en un mundo de fines tiene sentido la palabra "azar" (F. Nietzsche, "La gaya ciencia”, §109).

${ }^{34}$ Según Nietzsche, el problema no es que el lenguaje sea ficcional sino el olvido de que lo es. El olvido de que éste se ha generado como una herramienta para afirmarnos como existencia, en otras palabras, que se ha dado como "necesidad"; pero en su lugar creemos, que mediante las representaciones abstractas del lenguaje podemos acceder a la esencia de las cosas, a la verdad del mundo. Es así, que en el momento en que se deja de considerar al lenguaje como una estructura externa que simula al mundo desde metáforas, las metáforas viven un proceso de transmutación y pasan de ser simulacro y ficción a convertirse en creencia, dogma y verdad
} 
joven filólogo cree estar presenciando en Alemania el renacimiento de esta "sabiduría dionisíaca". Los referentes de esta resurrección serán, por un lado, Schopenhauer, autor que, según Nietzsche, restaura la resignación trágica a través de su voluntarismo pesimista; y, por otro lado, Wagner, cuya música se le presenta al joven Nietzsche como el resurgimiento del espíritu trágico, espíritu que acerca al hombre de manera estética al mundo, inspirándolo a relacionarse con éste de una manera activa-vital. ${ }^{35}$

\section{Segundo momento: divorcio con el romanticismo}

Nietzsche tendrá un segundo momento en su relación con los griegos. Luego de las "Intempestivas" y el quiebre con Wagner, el filólogo aminoraría el espíritu romántico idealizador que había generado con los griegos arcaicos del siglo VI, abandonando, a su vez, la fe que tenía hacia las figuras que pensaba restaurarían el ethos inspirador del genio arcaico. Así dirá el mismo al respecto de su cambio:

[...] en un comienzo me abalance sobre este mundo moderno con algunos gruesos errores y sobreestimaciones, y en todo caso como un esperanzado. Entendía [...] el pesimismo filosófico del siglo diecinueve como si fuese el síntoma de una fuerza superior del pensamiento, de una valentía más osada, de una plenitud más victoriosa de la vida, que la que había sido peculiar al siglo dieciocho [...] De la misma manera me compuse una interpretación de la música alemana como siendo la expresión de un poderío dionisiaco del alma alemana: en ella creía escuchar el terremoto con que finalmente se liberaba una fuerza originaria acumulada desde antiguo [...] Se ve que yo desconocía en aquel entonces lo que constituía el carácter más propio tanto del pesimismo filosófico como de la música alemana - su romanticismo [...] Schopenhauer y Richard Wagner, para nombrar a aquellos románticos más famosos y más explícitos que fueron mal comprendidos por mí en aquel entonces. ${ }^{36}$

En resumen, los románticos alemanes se sentirán muy vinculados al mundo clásico. Consideran que el legado griego los constituye culturalmente. En este sentido, la evocación helena representará otro referente de identificación nacional. Nietzsche criticará esta lectura política que se hace de los griegos, fundamentalmente, por considerar que las obras realizadas por éstos han sido idealizadas con fines políticos y vaciadas del espíritu genial que las llevó a ser constituidas. En otras palabras, critica que se haya transformado a los griegos, en unas simples reliquias de admiración pasiva, esto, en vez de considerarlos como ejemplos para la movilización activa. Sin embargo, en último término, Nietzsche terminará por realizar lo mismo que acusa, ya que también acaba por idealizar a los griegos, en esta ocasión a los del periodo arcaico. Intenta, de manera forzosa, una replicación palingenésica del mundo griego en lo alemán por medio de las figuras de Schopenhauer y Wagner. Nietzsche posteriormente advertirá este error, dejará atrás esta interpretación romántica-instrumental de los griegos, para comenzar a analizarlos desde una óptica más crítico-cultural.

[Friedrich Nietzsche, "Sobre verdad y mentira en sentido extramoral”, en Obras completas, vol. I, ed. Diego Sánchez Meca, (Madrid: Tecnos, 2011), 609-617].

${ }^{35}$ Nietzsche veía un resurgir en la música wagneriana del espíritu aristocrático germánico. Consideraba que en los dramas musicales wagnerianos se recuperaba a las "antiguas sagas y leyendas" alemanas, en las que se deja en evidencia "la pureza de un supuesto espíritu nacional privilegiado" (Nietzsche, "Aurora", 321). En otras palabras, para Nietzsche, la obra de Wagner representaba una forma de "adoración romántica del genio y del héroe nacional", una perspectiva artística muy distante a la racionalista-ilustrada (Ibíd., 624).

${ }^{36}$ F. Nietzsche, "La gaya ciencia", 884. 


\section{Crítica al espíritu rousseauniano-revolucionario y a su componente cristiano}

Como bien advertimos, el romanticismo tendrá expresiones ambivalentes: por un lado, rescatará el talante heroico-aristocrático de la cultura; pero, por otro lado, valorará las expresiones comunitarias. Con respecto al segundo caso (valoración del comunitarismo), Nietzsche criticará en particular dos perspectivas: la rousseauniana comunitaria y la germano-cristiana.

\section{Rousseau. Antecedentes generales}

Rousseau (1712-1778) es una figura paradigmática, sus ideas y planteamientos, a contracorriente de su época, cuestionarán la noción racionalista de la ilustración y se centrarán en lo emocional (por eso también se ve en su figura al romántico prototípico). En general, se puede decir que el carácter romántico de la propuesta rousseauniana es generalizable en cuatro ideas:

Valoración de la autonomía y los sentimientos subjetivos en detrimento del excesivo racionalismo de la ilustración. Rousseau mismo sería un modelo de esta idea al registrar sus impresiones románticas en sus autobiográficas Confesiones (1781-1788).

Imaginario de que existe un estado pre-social (estado de naturaleza), no contaminado por el espíritu de las instituciones asentadas en la propiedad privada, ${ }^{37}$ en donde el hombre se muestra como es en esencia: un ser bondadoso y benevolente.

Reprobación y condena de la corrupción y la desigualdad de las instituciones asentadas en la propiedad privada, y valorización de la idea de resistencia a las mismas.

Propuesta de un nuevo "pacto social" en el cual participen todos. Estipulado según los lineamientos de la "voluntad general".

En estas ideas, según Nietzsche, se encontrarían los gérmenes, por un lado, de la revolución; y, por otro lado, de la democracia. El filólogo irá en contra del ideario esbozado por el ginebrino, esto sobre todo en su periodo de mayor madurez, combatiendo decididamente estas semillas revolucionarias y gregarias que lanza Rousseau.

\footnotetext{
${ }^{37}$ El desarrollo de la propiedad privada y las instituciones que giran alrededor de ésta, serán los influjos compartidos que desviarán al hombre de su inocente "estado de naturaleza", corrompiéndolo y creando un modelo de civilización opresiva y desigual, situación que mantendría a los menos favorecidos en una condición de esclavitud social. Para Rousseau la forma de revertir este negativo camino tomado es contagiándose con el moralmente incorruptible "estado de naturaleza" primigenio.
} 


\title{
Crítica a la excesiva valoración de la autonomía y la subjetividad de Rousseau
}

Nietzsche criticará la valoración a la autonomía y la subjetividad propias promocionada por Rousseau, ya que considera que este sentir se cimenta sobre un idealismo sentimentalista y arbitrario. Dirá al respecto del ginebrino: "Hay personas que querrían imponer a cualquiera un sí o un no en relación a su persona en conjunto; pertenece a ellos Rousseau; sus delirios de grandeza surgen de su delirante desconfianza hacia sí mismo". ${ }^{38}$

\section{Crítica de la idea de "estado de naturaleza"}

Nietzsche también evaluará de forma negativa la idea rousseauniana del "estado de naturaleza" como etapa pre-social no corrupta y degradada. El filólogo considera que la dicotomía moral que establece Rousseau, que señala que la sociedad y sus instituciones son malas y la naturaleza en su esencia es la buena, no es más que puro idealismo especulativo sin antecedentes que sostengan lo enunciado de forma concreta:

\begin{abstract}
Al principio los hombres se imaginaron a sí mismos dentro de la naturaleza: se veían por todas partes, a sí y a sus semejantes, esto es, sus pensamientos malvados y caprichosos, escondidos como quien dice entre nubes, tormentas, fieras salvajes, árboles y hierbas: inventaron entonces la «naturaleza mala». Vino luego un tiempo en que se vieron ya fuera de la naturaleza, la época de Rousseau: estaba uno tan harto de los demás que necesitaba sin falta un rinconcito en el mundo en que no apareciera el hombre con sus penas: se inventó la «naturaleza buena. ${ }^{39}$
\end{abstract}

Nietzsche, a diferencia de Rousseau que cree que retornar a la naturaleza es un acto de purificación moral, considera que el retorno es un acto de afirmación vital, que consta en proyectarse en el devenir de la existencia de forma activa, esto desde la pluralidad de fuerzas que integran lo humano; en otras palabras, piensa en el retorno a la naturaleza desde una óptica vitalista-afirmadora y no idealista-moral:

También yo hablo de «vuelta a la naturaleza», aunque propiamente no es un regresar, sino un ascender: ir hacia arriba en dirección a la naturaleza y a la naturalidad elevada, libre, incluso horrorosa, una naturaleza tal que juega con grandes tareas, que tiene derecho a jugar con ellas [...] Pero Rousseau ¿a dónde quería él regresar propiamente? Rousseau, el primer ser humano moderno, idealista y canaille en una sola persona; el que necesitaba la «dignidad» moral para soportar su propio aspecto; enfermo de vanidad desenfrenada y de autodesprecio desenfrenado. También este engendro, que se ha tendido en el umbral de la época moderna, quería la «vuelta a la naturaleza» ¿a dónde, preguntamos de nuevo, quería regresar Rousseau? $?^{40}$

\footnotetext{
${ }^{38}$ F. Nietzsche, Fragmentos póstumos, 1882-1885, vol. III, 139.

${ }^{39}$ F. Nietzsche, "Aurora", 499.

${ }^{40}$ Friedrich Nietzsche, “Crepúsculo de los ídolos”, en Obras completas, vol. IV, ed. Diego Sánchez Meca (Madrid: Tecnos, 2016), 683.
} 


\section{Crítica del espíritu romántico-revolucionario alentado por Rousseau}

En tercer lugar, Nietzsche va ir en contra del espíritu romántico-revolucionario que promueve de forma embrionaria Rousseau, aquello, al condenar la corrupción y la desigualdad que producen las instituciones asentadas en la propiedad privada:

Yo odio a Rousseau incluso en la Revolución: la Revolución es la expresión en la historia universal de esta duplicidad de idealista y canaille. La farce [farsa] sangrienta con la que se representó esa Revolución, su "inmoralidad", me importan poco: lo que yo odio es su moralidad rousseauniana, las pretendidas "verdades" de la Revolución, con las que esta continúa teniendo efecto y persuadiendo en su favor a todo lo que es superficial y mediocre ¡La doctrina de la igualdad! ${ }^{41}$

Nietzsche cree en este sentido que la revolución es un contramovimiento moral, el cual busca hacer prevalecer el espíritu gregario, una perspectiva vital decadente, en vez del aristocrático, una perspectiva vital ascendente:

Nuestra hostilidad a la révolution se refiere no a la farce sangrienta, a la «inmoralidad» con la que se desarrolló; sino más bien a su moralidad gregaria, a sus «verdades», con las que sigue actuando y actuando, a su contagiosa idea de «justicia, libertad» con la que enreda a todas las almas mediocres, a su derrocamiento de las autoridades de los estamentos superiores. $^{42}$

Para Nietzsche, la revolución como idea crece gracias a los sentimientos de resentimiento y revanchismo de la plebe. Esto, "pues por debajo de todo romantisme [romanticismo] gruñe y ansía con ganas el instinto de venganza de Rousseau." ${ }^{43}$ Nietzsche considera que el trabajo de emancipadores como Rousseau no representan expresiones que incrementen la cultura o sean un aporte en términos creativos, sino que son incursiones que extrapolan el rencor particular por ciertas condiciones miserables que se padecen como consecuencia de las disposiciones de orden social.

Rousseau es un síntoma del desprecio de sí mismo y de la encendida vanidad — signos ambos de que falta voluntad dominadora: moraliza y como hombre de rencor busca la causa de su miserabilidad en los estamentos dominantes. ${ }^{44}$

Es así que el resentimiento es transformado por Rousseau en un ideario movilizador, que convoca las disposiciones de forma emocional hacia el revanchismo, pero un revanchismo que inmediatamente consumado se vuelve estrecho, ya que, según Nietzsche, la masa carece de un espíritu creativo-afirmador, y en este contexto, vuelve a ser ésta nuevamente manipulada por los emancipadores románticos, como por ejemplo, espíritus decadentes como Robespierre; o, por nuevos ordenadores, espíritus ascendentes como Napoleón. Así lo hace ver un Nietzsche maduro:

[...] la superstición de Rousseau, que creía en una originaria y milagrosa mas sepultada bondad de la naturaleza humana, y atribuía toda la culpa de esa sepultación a las instituciones de la cultura, en la sociedad, el Estado y la educación. Desgraciadamente, gracias a la

\footnotetext{
${ }^{41}$ Ibíd, 683.

${ }^{42}$ F. Nietzsche, Fragmentos póstumos, 1885-1889, vol. IV, 271.

${ }^{43}$ F. Nietzsche, "Crepúsculo de los ídolos", 655.

${ }^{44}$ F. Nietzsche, Fragmentos póstumos, 1885-1889, vol. IV, 281
} 
experiencia histórica se sabe que todas esas revoluciones hacen resurgir las energías más salvajes, las que derivan de los horrores y excesos, hace tiempo enterrados, de las épocas más oscuras: es decir, que una revolución puede ser una fuente de fuerza para una humanidad que se ha vuelto débil, pero nunca jamás un organizador, un arquitecto, un artista o perfeccionador de la naturaleza humana. ${ }^{45}$

\title{
Crítica de la valoración del cristianismo alemán y de los componentes cristianos del pensamiento de Rousseau
}

Nietzsche también batalla en contra de la idea de que los diferentes Estados alemanes tienen un volkgeist común observable en su histórica dimensión religiosa: la cristiana.

Ante este sentir romántico-nacionalista que reivindica el pasado cristiano como expresión pangermánica, Nietzsche señalará que: efectivamente, hay que volver a los orígenes, pero no en función de rescatar la herencia cristiana alemana como representación simbólica de unidad, sino, por el contrario, hay que hacerlo como una forma de limpieza y de purificación de todo rastro cultural de esta religión. Nietzsche considera que el influjo del cristianismo ha ido desfigurando y reprimiendo el carácter de la cultura germánica, como la idea del héroe teutón y sus valores, y a su vez han ido promoviendo regímenes de gobierno "decadentes" como la democracia. Para el filólogo, la democracia es de raigambre latina y cristiana, es decir, lo opuesto a la potencia espiritual alemana que hunde sus raíces en la cultura aristocrática-heroica del germanismo medieval. Así da cuenta Nietzsche de las dos visiones de mundo que se enfrentan: la democrático-liberal de raigambre cristiana contra la aristocrático-guerrera.

\begin{abstract}
Ante todo, no me queda más remedio que ver en el movimiento nacionalista que domina en la actualidad, y en la expansión simultánea del sufragio universal, los efectos del temor a la guerra, aún más, en el trasfondo de esos movimientos diviso como los que verdaderamente tienen miedo son esos ermitaños del dinero apátridas, verdaderamente internacionales, los cuales, con su carencia natural del instinto estatal han aprendido a abusar de la política. ${ }^{46}$
\end{abstract}

En el fondo, Nietzsche critica al pensamiento de Rousseau porque ve en éste un culto a la moral cristiana:

Formas más escondidas del culto del ideal moral cristiano. - El concepto blando y cobarde de «naturaleza» que ha sido introducido por los entusiastas de la naturaleza ( - separado de todos los instintos para lo terrible, lo inexorable y lo cínico incluso de los aspectos «más bellos») una especie de intento de leer en la naturaleza esa «humanidad» moral-cristiana, el concepto de naturaleza de Rousseau, como si la «naturaleza» fuera libertad, bondad, inocencia, equidad, justicia idilio...siempre el culto de la moral cristiana en el fondo... ${ }^{47}$

Es así que Rousseau como sus discípulos (Robespierre, Kant, Schopenhauer, etc.) representarán para Nietzsche, los promotores de un movimiento decadente que irá influenciando a todo espectro cultural y dispositivo formativo, el artístico, el filosófico y el

\footnotetext{
${ }^{45}$ Friedrich Nietzsche, "Humano demasiado Humano, I", en Obras completas, vol. III, ed. Diego Sánchez Meca (Madrid: Tecnos, 2014), 233.

${ }^{46}$ F. Nietzsche, Fragmentos póstumos, 1869-1874, vol. I, 294.

${ }^{47}$ F. Nietzsche, Fragmentos póstumos, 1885-1889, vol. IV, 355.
} 
histórico, por ejemplo, generando con esto una "unidad-cultural" retroactiva, a la cual Nietzsche combate:

Mi lucha contra el siglo XVIII de Rousseau, contra su «naturaleza», su «hombre bueno», su creencia en el dominio del sentimiento - contra el ablandamiento, debilitamiento, moralización del hombre: un ideal que nació del odio a la cultura aristocrática y es in praxi el dominio de resentimientos desenfrenados, un ideal inventado como estandarte para la lucha.- la moralidad del sentimiento de culpa del cristiano la moralidad del resentimiento (una actitud de la plebe). ${ }^{48}$

\section{El enfoque que valoriza Nietzsche de la historiografía romántica}

Hemos visto, por un lado, que Nietzsche critica la perspectiva política burguesa que lee la historia funcionalmente con lo que se pretende desde lo político: crear una nación unificada tanto política como económicamente; por otro lado, también hemos revisado la valoración negativa de Nietzsche de la perspectiva político-social de la historia influenciada por Rousseau, que dispondrá de la historia desde el ámbito de la justicia, ámbito que, según Nietzsche, alienta el resentimiento y el revanchismo de los estamentos menos favorecidos por las disposiciones de orden social heredados. Nietzsche denunciará que, tanto desde el proyecto político burgués como desde el social-comunitario, se idealizará de forma artificiosa el pasado. Lo único que consideraría Nietzsche de los estudios históricos románticos será el rescate que hace la corriente de las acciones del mundo heroico-germánico. Esto, principalmente, porque reivindica el modo de ser aristocrático. Con respecto a esta reivindicación del carácter aristocrático, podría considerarse a simple vista que Nietzsche, en último término, también termina por realizar aquello que tanto crítica, esto es: politizar la historia; ya que al valorar una cierta tendencia, la aristocrática, del romanticismo, en detrimento de otras, la liberal-burguesa y la social-comunitaria, también en el fondo es asumir una perspectiva que es traducible en términos políticos. Sin embargo, interpretar la crítica nietzscheana fundamentalmente de esta forma sería a nuestra consideración un gran error, esto, porque cuando Nietzsche interpreta positivamente la tendencia romántica que rescata el pasado aristocrático, más que por alicientes políticos, idealistas o académicos, lo hace por consideraciones vitales. Para Nietzsche, la historia de lo heroico es una historia que, cuando es correctamente expresada, puede implicar a la vida. Implica a la vida, cuando su objetivo no es la rememoranza pasiva y vacía del pasado, sino cuando esta se efectúa como modelo inspirador para la acción.

La historia pertenece, sobre todo, al hombre de acción, al poderoso, al que libra una gran lucha y tiene necesidad de modelos, de maestros, de confortadores, que no puede encontrar en su entorno ni en la época presente [...] Que los grandes momentos en la lucha de los individuos forman una cadena, que ellos unen a la humanidad a través de los milenios, como crestas humanas de una cordillera, que para mí la cumbre de tal momento, hace largo tiempo caducado, sigue todavía viva, luminosa y grandiosa -es la idea fundamental de la fe en la humanidad que encuentra su expresión en la exigencia de una historia monumental... ${ }^{49}$

Cuando la historia es expresada desde una perspectiva monumental, los grandes hombres del ayer, que alguna vez devinieron afirmativamente sobre sus existencias logrando

\footnotetext{
48 Ibíd., 297.

${ }^{49}$ F. Nietzsche, "De la utilidad y los inconvenientes de la historia para la vida", 703.
} 
grandes proezas, pasan a convertirse, no en meros personajes de un pasado lejano, sino en figuras presentes; son pedagogos trans-históricos que a las nuevas generaciones les infunden inspiración y aliento; esto, porque ayudan a pensar que lo grande alguna vez fue posible, y puede nuevamente volver a serlo. Tal como los griegos arcaicos, los héroes germanos o Napoleón empujaron con su espíritu a la civilización, también lo podrían hacer las nuevas generaciones, esto si se contagian de ese mismo espíritu activo. Así lo refiere Nietzsche:

¿En qué forma le sirve, pues, al ser humano del presente la concepción monumental del pasado, la ocupación con lo clásico e infrecuente de tiempos pretéritos? Extrae de ella la seguridad de que lo grande alguna vez se dio, en todo caso fue posible y, en consecuencia, volverá a ser posible alguna $\mathrm{vez}^{50}$; avanza él más animado, pues ha quedado vencida la duda que lo asaltaba en horas de debilidad, la duda de que acaso aspirara a lo imposible. ${ }^{51}$

En este sentido, lo que apreciaría Nietzsche de este rescate de la tendencia historiográfica romántico-aristocrática, es que rememora la cultura del individuo de acción que se proyecta en la existencia afirmativamente. Este hombre activo busca ejercer su voluntad al margen de un bien y de un mal codificados. Es decir, no juzga en nombre de la moralidad heredada sino juzga de acuerdo a su voluntad. Su voluntad no se ejerce, por tanto, como buena o mala, sino simplemente como voluntad. Para Nietzsche, este hombre de acción vive la existencia recurriendo constantemente al polo "olvido", es capaz de desapegarse del pasado y del exceso de memoria que provoca el "impulso anticuario"; y como un niño sin prejuicios ni miedo, experimenta creativamente sobre el mundo. Ello también explica el concepto de "fuerza plástica" desde el que Nietzsche piensa la acción de estos héroes en analogía con la creación artística. ${ }^{52}$

[...] a ese exceso de fuerzas plásticas capaces de curar a fondo, reproducir y reconstituir, que es precisamente el signo de la gran salud, ese exceso que le da al espíritu la peligrosa prerrogativa de poder vivir en adelante por ensayo y entregarse a la aventura. ${ }^{53}$

Para Nietzsche, la "fuerza plástica" es una cualidad que es propia de los cuerpos, esto teniendo en consideración que para el filólogo el cuerpo no es una sustancia ni una estructura inmutable, sino que es algo inacabado, un contenedor de diversas fuerzas que están en flujo y reflujo entre sí, en un juego continuo de impulsos en constante reacomodo ${ }^{54}$. Así lo señala:

\footnotetext{
${ }^{50} \mathrm{Si}$ bien Nietzsche valoriza la historia "monumental", también señala que un exceso de esta historia puede ser contraproducente a la vida. Sugiere en este sentido equilibrar la relación "monumental" de la historia con otras formas, como por ejemplo, la "anticuaria” y la "crítica” (Ibíd., 695-743).

${ }^{51}$ Ibíd., 704.

${ }^{52} \mathrm{El}$ impulso artístico creador del hombre de acción se manifiesta como ensayos y nuevas formas de habitar y de ser en el mundo, como novedosas maneras de re-territorializarse en lo dado.

53 Nietzsche, "Humano demasiado Humano, I", 72.

${ }^{54}$ Lo que hoy se conoce como homo-sapiens es solo otra de las múltiples disposiciones que han asumido las fuerzas en un centro de gravedad-cuerpo, pero esta forma, al igual que la de muchas otras, está lejos de mantenerse estática, de ser igual, la máquina del cuerpo contiene una serie de disposiciones de fuerza (instintos, afectos, sentimientos, pensamientos) que están en permanente tensión y reacomodo. Toda animalidad-vida, es en sí misma, en cuanto cuerpo, una superficie de inscripción en constante re-constitución, en constante resituarse en el devenir circunstancial de la naturaleza, es ella misma en sí devenir. De esta manera como el individuo no es un ente fijo, sino en permanente abertura, puede experimentar y explorar a partir de lo sensible, es decir del cuerpo, sobre el mundo.
} 
"[...] todo acontecer en el mundo orgánico es un someter, un enseñorearse, y que, a su vez, todo someter y enseñorearse es un nuevo interpretar, un ajustar [...]". 55

Nietzsche considera que al estar los fundamentos filosófico-epistémicos de los estudios históricos románticos erigidos sobre componentes suprasensibles, idea de nación, de telos, etc., proyectan un marco del quehacer historiográfico que incentiva una forma de historia que perjudica a la vida. ¿Por qué la perjudica? Porque, por un lado, construye narrativas, la historia como dimensión de maduración de los volkgeist, que cumplen funciones moralizadoras que inmovilizan la vida; la inmovilizan, al determinar el horizonte de desenvolvimiento de la libre voluntad humanas a ciertos parámetros de acción establecidos por estructuras de poder; $y$, por otro lado, porque alimentan el espíritu de resentimiento y venganza, que moviliza para ajusticiar, la historia como "evidencia" de transgresiones, pero que no crea ni ensaya. Así vista, la historia romántica, desde la perspectiva liberal y socialcomunitaria, solo promueve la inercia, esto, porque petrifica lo dado, o lo encauza a solo unos recorridos dispuestos instrumentalmente desde lo político.

En términos corpóreo-vitales, esta forma de presentar la historia, según pretensiones políticas y desde el sentimiento nostálgico, termina realzando la dimensión reactiva del cuerpo y no la activa, ya que la activa es dionisíaca. Esto quiere decir, que se despliega de forma creativa, imaginativa, delírica, experimental, sobre el devenir. ${ }^{56}$ Es por eso por lo que el filólogo solo valora la parte de la historiografía romántica que rememora el accionar individual de los grandes hombres, porque en el fondo, estos hombres son ejemplos arquetípicos de figuras que empujan los límites de la vida. ${ }^{57}$

\section{Reflexiones finales}

Para Nietzsche, en general, los estudios históricos románticos afectarían de manera negativa a la disciplina histórica y a la vida. Esto, porque dispondrán del pasado no en función de la utilidad que éste pueda prestar en el crecimiento de la potencia vital, sino que lo hacen desde disposiciones de proyectos políticos, el burgués-nacionalista y el social-comunitario. Estas disposiciones en vez de abrir la historia la clausurarán, aquello, porque subsumirán la historicidad hacia determinados parámetros de desenvolvimiento, convirtiendo de esta forma a los individuos en meros entes pasivos, a los cuales, por medio del aparataje cultural, se les constriñe del uso de sus fuerzas creativo-experimentales, los individuos en este sentido tienen que restringirse a ser meros espectadores de un acontecer que no pueden cambiar. Pero no solamente el romanticismo será para Nietzsche problemático por hacer de la historia un instrumento político usado para consolidar determinadas estructuras de poder, también lo es,

\footnotetext{
55 Friedrich Nietzsche, "La genealogía de la moral”, en Obras completas, vol. IV, ed. Diego Sánchez Meca (Madrid: Tecnos, 2016), 499.

${ }^{56}$ Friedrich Nietzsche, "El nacimiento de la tragedia”, en Obras completas, vol. I, ed. Diego Sánchez Meca (Madrid: Tecnos, 2011), 329-437.

${ }^{57}$ El impulso dionisiaco negado es precisamente el impulso artístico de lo corpóreo, el cual a su vez afirma a lo corpóreo, ya que el cuerpo, desde su "gran razón", entiende en su saber profundo que lo dado es dado siempre circunstancialmente (las estabilizaciones son evanescentes mientras que la transformación es lo regular), por lo que debe también como cuerpo, ir deviniendo constantemente, forcejeando con las nuevas realidades, creando y recreando nuevos instintos que respondan de forma eficiente a los cambios de este río (Friedrich Nietzsche, “Así habló Zaratustra”, en Obras completas, vol. IV, ed. Diego Sánchez Meca [Madrid: Tecnos, 2016],88-89).
} 
porque promueve valores nihilistas, ya que expresa una nostalgia permanente por el pasado, un anhelo de retorno que para Nietzsche no es posible corresponderlo con lo sensible; aquello, porque el pasado es una dimensión que ya fue atravesada por el devenir, y como ya fue atravesada solo puede existir como memoria, mas no ya como experiencia presente. Por eso el intento de reproducir el pasado en el presente es un movimiento improcedente, antinatural y debilitador de la vida; esto, porque una vida solamente puede crecer experimentando y probando nuevas maneras de habitar en el mundo, no reproduciendo constantemente lo mismo, una forma animal que siempre repita lo mismo se vuelve débil, aquello, porque se hace incapaz de hacer frente al devenir cambiante del mundo; una forma así, lo más probable es que en muy poco tiempo termine sucumbiendo.

En conclusión, Nietzsche denunciará tanto la instrumentalización política de la historia como la rememoración estéril del pasado, porque, según él, estos movimientos propician la decadencia de lo corpóreo-vital. Para el filólogo, solo desapegándose del exceso de memoria, luchando activamente, inclusive en contra de uno mismo, avanzando en delirio-dionisiaco y deviniendo creativamente, es como la fuerza plástica vital se puede incrementar potenciando a la vida, esto al empujar los límites de la misma. Y precisamente por esta razón, motivar la movilización activa y artística de la vida, que la tendencia romántica aristocrática será para Nietzsche evaluada de forma positiva, mientras que las tendencias nacional-burguesa y social-comunitaria del romanticismo son evaluadas negativamente.

\section{Bibliografía}

Jaime Aurell y otros, Comprender el pasado: Una historia de la escritura y el pensamiento histórico (Madrid: Akal, 2013).

Luis Eduardo Gama, "El carácter total del mundo. Esbozo de una ontología del caos en Nietzsche", Ideas y Valores, [vol.] 66, 165 (2017): 347-367.

Arsenio Ginzo, "Nietzsche y los griegos”, POLIS, 12 (2000): 85-135.

G. W. F. Hegel, Lecciones sobre la Filosofía de la Historia Universal (Madrid: Alianza, 1999).

Curt Janz, Friedrich Nietzsche: Infancia y juventud, vol.1 (Madrid: Alianza, 1978).

Friedrich Nietzsche, "Consideraciones intempestivas: David Strauss, el confesor y el escritor”, en Obras completas, vol. I, ed. Diego Sánchez Meca (Madrid: Tecnos, 2011), 641686.

Friedrich Nietzsche, "Consideraciones intempestivas: De la utilidad y los inconvenientes de la historia para la vida”, en Obras completas, vol. I, ed. Diego Sánchez Meca (Madrid: Tecnos, 2011), 695-743.

Friedrich Nietzsche, "Sobre verdad y mentira en sentido extramoral", en Obras completas, vol. I, ed. Diego Sánchez Meca (Madrid: Tecnos, 2011), 609-617. 
Friedrich Nietzsche, "El nacimiento de la tragedia”, en Obras completas, vol. I, ed. Diego Sánchez Meca (Madrid: Tecnos, 2011), 329-437.

Friedrich Nietzsche, "Humano demasiado Humano, I", en Obras completas, vol. III, ed. Diego Sánchez Meca (Madrid: Tecnos, 2014), 69-272.

Friedrich Nietzsche, “Aurora”, en Obras completas, vol. III, ed. Diego Sánchez Meca (Madrid: Tecnos, 2014), 469-648.

Friedrich Nietzsche, “La gaya ciencia”, en Obras completas, vol. III, ed. Diego Sánchez Meca (Madrid: Tecnos, 2014), 705-895.

Friedrich Nietzsche, “Así habló Zaratustra”, en Obras completas, vol. IV, ed. Diego Sánchez Meca (Madrid: Tecnos, 2016), 65-278.

Friedrich Nietzsche, "La genealogía de la moral”, en Obras completas, vol. IV, ed. Diego Sánchez Meca (Madrid: Tecnos, 2016), 441-513.

Friedrich Nietzsche, “Crepúsculo de los ídolos”, en Obras completas, vol. IV, ed. Diego Sánchez Meca (Madrid: Tecnos, 2016), 611-691.

Friedrich Nietzsche, Fragmentos póstumos, 1869-1874, Vol. I (Madrid: Tecnos, 2010).

Friedrich Nietzsche, Fragmentos póstumos, 1882-1885, Vol. III (Madrid: Tecnos, 2010).

Friedrich Nietzsche, Fragmentos póstumos, 1885-1889, Vol. IV (Madrid: Tecnos, 2008).

Gary Shapiro, "Estados y nómades: el mundo de Hegel y la tierra de Nietzsche", en Nietzsche y el devenir de la vida, ed. Vanesa Leem (Santiago: FCE, 2014), 291-307.

Friedrich Schiller, Sobre la educación estética del hombre en una serie de cartas (Mendoza: Universidad Nacional de Cuyo, 2016).

\section{Perfil}

Manuel Romero es Profesor de Historia y Magíster en Ciencias Políticas y en Filosofía. Sus líneas de trabajo principales son: Historia de la ciencia y la tecnología, Filosofía de la historia y Economía política. Actualmente se encuentra trabajando en libro enfocado en la historia de los semiconductores en el siglo XX.

\section{Profile}

Manuel Romero is Professor of History and Master in Political Science and Philosophy. His main lines of work are: History of science and technology, Philosophy of history and Political economy. He is currently working on a book focused on the history of semiconductors in the $20^{\text {th }}$ century. 
Fecha de recepción: 16 de enero de 2020

Fecha de aceptación: 18 de mayo de 2020

Publicación: 1 de julio de 2020

Para citar este artículo: Manuel Romero, "Las críticas de Nietzsche a las corrientes historiográficas románticas. Una evaluación desde lo corpóreo-vital", Historiografías, 19 (enero-junio, 2020), pp. 83-105. 